\title{
THE ROLE OF POLITICS AND INSTITUTIONAL ENVIRONMENT ON ENTREPRENEURSHIP: EMPIRICAL EVIDENCE FROM MOZAMBIQUE
}

\author{
Renato Pereira \\ rpereira@autonoma.pt \\ Integrated Researcher, OBSERVARE, Universidade Autónoma de Lisboa (UAL, Portugal). \\ Associate Professor at UAL. Guest Professor at ISCTE-IUL. \\ $\mathrm{PhD}$ in Management Sciences by Université Paris Dauphine.
}

Redento Maia Post-Doctorate researcher, OBSERVARE, Universidade Autónoma de Lisboa. Full Professor at the Faculty of Economics of Agostinho Neto University (Angola). Doctor of Economics from Sofia University of Economics.

\section{Abstract}

This work investigates the relationship between the political and institutional environment and the development of entrepreneurship in Mozambique. Taking a literature review approach and using collected empirical data from interviewing 10 individuals playing different roles with impact on county's entrepreneurial landscape, results support existing theory and suggest that this African country still has a long way to go in what relates governmental action to entrepreneurial development.

\section{Keywords}

State, Policy, Entrepreneurship, Mozambique, Africa

\section{How to cite this article}

Pereira, R; Maia, R (2019). "The role of politics and institutional environment on entrepreneurship: empirical evidence from Mozambique". JANUS.NET e-journal of International Relations, Vol. 10, N.0 1, May-October 2019. Consulted [online] on the date of the last visit, https://doi.org/10.26619/1647-7251.10.1.7

Article received on October 17, 2018 and accepted for publication on February 4, 2019 


\section{THE ROLE OF POLITICS AND INSTITUTIONAL ENVIRONMENT ON ENTREPRENEURSHIP: EMPIRICAL EVIDENCE FROM MOZAMBIQUE}

\section{Renato Pereira Redento Maia}

\section{Introduction}

The role played by the State, local authorities, governments, institutions, and public policies on entrepreneurship development has long been investigated by scholars of different fields within social sciences.

In the case of Africa, the importance of understanding this topic is of key importance because of the tested relationship between entrepreneurship and economic growth in the continent (e.g. Adusei, 2016) and the low level of economic development in many African countries.

Some of the key elements that relate the 'State' action with entrepreneurship are the institutional environment provided by governments, where bureaucracy plays a dramatic role, but also the start-up cost, the (lack of) transparency of public fee schedules, the (lack of) investment on human capital, the (lack of) coordination between governmental policy-makers and policy-implementing public servants, and the suspicion /fear politicians feel about entrepreneurs, among other factors.

The purpose of this work is to empirically explore the key relationships identified in existing literature in one of the least developed countries in Africa, thus contributing to increase the knowledge on both entrepreneurship and State role in Mozambique.

\section{Entrepreneurship and politics in Africa}

\subsection{Entrepreneurship, economic development, and public policy}

Governments all over the world have been using entrepreneurship development as an answer to one of the most challenging economic issues of any democratic regime: unemployment (e.g. Mehari \& Belay, 2017). Because of that, economists have been extensively testing the relationship between entrepreneurship and economic growth which has created a strong base to inform governments and policy makers about what they could and should do about it. In a very provocative paper, Shane (2009), points out two very important elements for reasoning on this subject:

(i) countries with most entrepreneurs as a percentage of the population are poor countries, not rich countries; and

(ii) (ii) only a tiny percentage of all start-ups, the so called 'gazelles', do actually have a significant impact on job and wealth creation. Let us address these two tested 
hypotheses. A striking economic evidence is that when people get more educated and their salaries increase, the opportunity cost of leaving the labor market increase and the motivation to run the risk of starting a new venture decrease. When unemployment goes up, many people are pushed to start a business either because they have no other way of making a living or because governments offer them incentives and benefits to do so. This leads to a significant increase in entrepreneurial activity in the market based on unfit entrepreneurs with small potential of generating profitable job-creating businesses and a tremendous diversion of financial resources that could be used to develop effective entrepreneurship through appropriate instruments, such as venture capital funds.

Further interesting economic research on entrepreneurship can be found in Mthanti \& Ojah (2017). Entrepreneurial orientation is important for economic growth, not simply entrepreneurial activity. Governments must choose, in priority, to pull both entrepreneurial-oriented ventures and entrepreneurial-oriented incumbents. It is reminded the existence of significant research supporting policy and institutional causes for Africa's poverty but few studies address the real impact of entrepreneurship on this issue.

Naudé (2013) had already made the point that policy must focus on pulling entrepreneurial ability instead of entrepreneurial activity. 'Improving the quality of entrepreneurial ability means not only improving the skills and education of entrepreneurs, their human capital, but focusing on the innovative abilities of entrepreneurs. It is innovative entrepreneurship that is most desirable for growth. Innovation policy ought therefore to be a central focus of entrepreneurship promotion in developing countries as it is in advanced economies. Entrepreneurs in developing countries have a much greater propensity for innovation than is often recognized in the literature or by policy-makers'.

Although it takes some time before innovation policies and capital investment produce relevant impact on economic growth in Africa, training, skill acquisition, knowledge sharing, ease of access to capital, infrastructure development particularly in telecommunication, and others leading to patent increase, all these factors favor overcoming this challenge (Ojeaga, 2015).

The link between innovative entrepreneurship and access to education, and expenditure on training was also confirmed by Robson et al (2009). Surprisingly, this research reveals that older ventures are more innovative than younger ventures and better-established markets are also more likely to foster innovation than new markets, stressing the importance of institutional variables for opportunity-driven entrepreneurship.

Schillo et al (2016) also confirms the importance of institutional variables to entrepreneurship. Among the four dimensions considered, regulation weights less than normative, cognitive, and conducive dimensions.

Other interesting economic research (Islam, 2015) found out that entrepreneurial activity and government size are negatively correlated, which seems to be an interesting proxy about the way many African governments perceive entrepreneurship. 
Juma et al (2017) summarized the role of government (and public agencies) on entrepreneurship: to facilitate (or block) entrepreneurial development by means of legal infrastructure, human capital development, and providing funding facilities.

Difficult access to capital, inconsistent governmental regulation, and unavailability of business locations are referred by Kiss et al (2012) as issues where government could contribute positively in countries such as Kenya or Ghana. In low developed countries with significant institutional deficiencies, entrepreneurs don't count on government to overcome venture obstacles.

When studying public governance and economic-related effects, Asongu \& Nwachukwu (2016) highlight three broad concepts:

(i) political (voice and accountability, and political stability /no violence),

(ii) economic (government effectiveness and regulation quality), and

(iii) institutional (corruption-control and rule of law).

The conceptual model of fostering serial entrepreneurial development of AmankwahAmoah (2018) place government as an exogenous factor, impacting at two levels:

(i) government policy (regulatory constraints); and

(ii) governmental barriers.

Taking the case-study of Ghana, the author mentions that the 30-year period following the independence attained in 1957 was characterized by active policies to suppress entrepreneurship because entrepreneurs were often seen as 'potential political threats'. Therefore, a foreign investment policy of Western multinationals was fostered. After that, there was a shift towards a friendly regulatory environment for small businesses and indigenous entrepreneurs but this was not exactly backed by appropriate governmental support, financial resources, and real favorable regulatory conditions. This investigation reports little public support to develop managerial capabilities and entrepreneurial skills until early this century. As a result, confidence was not built by local firms and capabilities to attract investor attention were not developed. Institutions treat entrepreneurial ventures with the suspicion of having 'foreign owners', and entrepreneurs of being 'corrupt', 'fraudsters' and 'cheaters'. Public sector bureaucracy is an additional issue. Combined, these factors decrease the odds of reaching a positive entrepreneurial activity. It is suggested that government designs policies to destigmatize entrepreneurial failure among indigenous business owners and promote rebounds. Corroboration of public investments in 'human capital development', 'good governance', and 'infrastructural development for technology and innovation' is also provided.

It is important to accentuate that foreign investment will not produce the desired outcome in Africa if it does not increase indigenous entrepreneurship (Mota \& Moreira, 2017). Hence the importance to combine policies to both attract external and internal entrepreneurs and business people.

McDade \& Spring (2005) provide additional evidence on the distress of African governments about the development of African ventures, limiting their possibilities of growth. 'Government leaders were suspicious that a strong private sector comprised of their own citizens might threaten their own powers and privileges'. Consequently, after 
all these years, Africans still own less than one third of large industrial companies in the continent. The new generation of African entrepreneurs demand 'business-friendly laws and regulations, government policies, and programs', look for dialoguing with policymakers but reject 'government patronage'.

Still working upon Ghana's data, Hilson et al (2017), in the framework of artisanal and small-scale mining entrepreneurship, identified three key areas of public policy concern:
(i) licensing;
(ii) policy apparatus; and
(iii) funding.

On the same stream of thought, Amankwah-Amoah et al (2018a) posit the critical importance of government for purposes of technology adoption in Africa through 'promoting national identification', 'societal involvement', and 'improving educational infrastructures'. Policy lacuna has been identified as the region's critical gap in supporting technology development. Choices must be made about the trajectories of innovation to be pursued supported by state-driven initiatives. On the other hand, Amankwah-Amoah et al (2018b) highlight some institutional constraints to technology-driven entrepreneurship. Although democracy became more widespread in Africa recently, severe government intervention is banal with excessive public employment and socialism legacy in many countries. This led to go backwards in terms of entrepreneurial orientation when compared to late colonial days and even before that. Classic over-bureaucracy and 'red tape' problems are remembered. Lack or even absence of intellectual property is another weakness of most African entrepreneurs. The example of renewable energy development is provided as an opportunity to entrepreneurial development in Africa given massive infrastructural deficiencies and current monopoly inefficiencies.

Institutions have a significant impact on firm behavior and consequent competitiveness. Barasa et al (2017) mention the role on environmental uncertainty and transaction costs but also on the way businesses coordinate with each other. Another significant hint of this research is the description of institutional quality, which includes:

(i) the process of governmental appointment, controlling, and change;

(ii) the ability to generate and carry-on strong policies; and

(iii) the way they relate with citizens and firms. When compared to other regions of the world, Sub-Saharan Africa performs worse in the enforcement of the rule of law, regulatory quality, level of corruption, and government effectiveness. Good institutional functioning is mandatory for entrepreneurship and innovation.

Another stream of thought, developed by Brixiova (2010) and Brixiová et al (2015) and reflecting the work of the African Development Bank, stress the importance of clearing the way for firm creation, decreasing taxes and cutting incorporation costs. Based on the evidence that these countries have significant budgetary limitations, policy selectivity and sequencing is of utmost importance. Subsidies to start up entrepreneurial ventures, and support to entrepreneurship training programs are identified as important policies to stimulate entrepreneurship. 
In what matters innovation, for example, Cunningham (2015) identified that one of the major shortcomings of African countries is the information transmission between those who adopt policies, typically top government officers, and those who must implement those, mainly public servants. Public sector support is reported to be weak based on individual judgement that those entrepreneurs potentially benefiting from governmental support are privileged when compared to the general population because they were eligible for support based on a superior skill-set, including previous access to education.

When it comes to assess the way businesses can be informed about their regulatory environment, Geginate \& Saltane (2016) report that in Africa this is very opaque. In the Sub-Saharan region, only 4 out of 46 countries provide decent and stable information about fee schedules in the following four categories:

(i) business incorporation;

(ii) building permits;

(iii) electricity connection; and

(iv) property registration.

One of the reasons for this institutional weakness in Africa relates to one specific particularity of the historical legacy: before colonialism, there was up to 10,000 different states and autonomous groups in Africa generating cultural distance, community dispersion, and lack of common purpose. On the other hand, recent international integration of many of these states led them to develop budgetary and fiscal controlling systems in line with every international compliance requirements (George et al, 2016).

Some good examples of positive governmental impact on African entrepreneurial development are also reported in the literature. M-Pesa, a case of 'ex ante investment with ex post justification', available in several countries, is a paradigmatic example of good institutional entrepreneurship (Kshetri, 2016).

\subsection{Politics and policymaking in Mozambique}

Mozambique is one of the least developed countries in the world (LDCs) and ranks very poorly in the main international indicators of development, like the Human Development Index, and in every investment climate /doing business reports.

'This is related to poor access to finance, perceived prevalence of corruption, inefficient government bureaucracy, inadequate infrastructures, and the education level of the workforce' according to Libombo \& Dinis (2015). Like in many African countries, governmental action on entrepreneurship has been oriented to reduce economic exclusion rather than to capability building. Probably because of that, entrepreneurs remain a negatively-perceived professional group in terms of social status.

In such environments, entrepreneurial ventures 'tend to respond to increased bureaucracy by fortifying their political engagement with bureaucrats and by accentuating their political influence over bureaucracy-related policy making' (Luo \& Junkunc, 2008).

In terms of political regime, Mozambique is, in formal terms, a democracy. It has been classified as an 'electoral autocracy' by Lührmann et al (2018) ever since the end of the civil war in late 1992. The ruling party since 1975, FRELIMO, is then 'the party'. 
In what matters entrepreneurship, government has been increasing references to the importance of that variable to policymaking and to the broad economic agenda. Some of the current government measures that aimed at impacting entrepreneurial potential are:

The $2^{\text {nd }}$ government's top priority, according to the 2015-2019 five-year plan, is 'to develop human and social capital'. Within that priority, the strategic goal \#1 is 'to promote an inclusive educational system, effective and efficient, which guarantees the acquisition of required capabilities in terms of abilities, management and attitudes that answer the needs of human development'. Within that strategic goal, the priority action I) is 'to establish programs and synergies with higher, technical, professional, research, and technological education institutions that contribute to stimulate innovation and entrepreneurship'.

The $3^{\text {rd }}$ government's top priority, according to the same 2015-2019 five-year plan is 'to promote job creation and increase productivity and competitiveness'. Within that priority, the strategic goal \#1 is 'to increase production and productivity in all sectors of economic activity, especially in agriculture'. Within that strategic goal, the priority action i) is 'to consolidate and expand poles of research and dissemination of technologies and innovation for communities, and the priority action $\mathrm{n}$ ) is 'to promote funding for innovation and research projects addressing socio-economic development challenges'.

\section{Empirical study}

\subsection{Data samples and research methods}

The goal of this study is to investigate the impact of government on entrepreneurship in Mozambique. Using the perspective of five different actors, selected according to their theoretical relevance to the subject:

(i) governmental policy-maker - 1 individual;

(ii) public servant policy-implementer - 1 individual;

(iii) funding provider - 1 individual;

(iv) expert -1 individual;

(v) entrepreneur - 6 individuals; a field study in the country was designed for this purpose alone.

The research is of qualitative nature. This sample has no statistical relevance on the population and no inferential conclusions are to be taken.

Actors from categories (i), (ii), (iii) and (iv) are from Maputo-City province, three men, one woman. Actors from category $(v)$ are from the following provinces: Maputo-City, Maputo-Province, Sofala, Tete, Niassa, and Nampula, one per location, four men, two women.

Interviewees were identified through double-checked personal referral and were duly briefed about the aims, scope, and process of the investigation. They were initially contacted by e-mail and after confirming availability for the research they were recontacted, this time through mobile phone call. Further contacts were established through WhatsApp or Skype messaging facilities. Anonymity was demanded by all 
participants and was guaranteed through the form of a print-out signed non-disclosure agreement entitled 'Statement of Ethical Conduct Under Commitment of Honor'.

All interviews were face-to-face conducted in Portuguese language and were audiorecorded in the interviewer's smart phone device. They took place in the capital town of Maputo, between the $17^{\text {th }}$ and the $23^{\text {rd }}$ of May, 2018, at the preferred location of each interviewee, either the interviewee professional or business office or the interviewer hotel room.

An open-question approach was employed although a basic script of 12 topics was used to conduct the discussion. Accuracy and memory-related notes were taken from each interview. The longest interview took $03 \mathrm{~h} 17 \mathrm{~m}$ and the shortest $00 \mathrm{~h} 48 \mathrm{~m}$. The average interviewing time was $02 \mathrm{~h} 04 \mathrm{~m}$. it was agreed that, if in doubt, interviewees would be later re-contacted for punctual clarifications.

Data was then treated using interview content analysis. Each interview was subject to repeated hearings during the $24^{\text {th }}$ of May, 2018, the first day after concluding the data collection, to make sure the right meaning of each discussion was captured and key sections were subject to written transcription. Two interviewees were re-contacted on the $25^{\text {th }}$ of May, 2018 through FaceTime live call, for miscellaneous clarification.

\subsection{Data exploration and findings}

All interviews observed the following chaining: first topic discussed was the policymaking process itself, and how it takes place in the country; second, the discussion about institutional constraints in the process of designing policies, such as bureaucracy, and ease to capital access; third topic, the type of judgment about and perceived threats arising from the entrepreneurs.

\section{(i) Interview with the governmental policy-maker - 1 individual}

The person in question had held a top position in the government of Mozambique in the past.

Policymaking was described as a sense-making exercise subject to somebody's initiative. There are different agendas guiding this process, not necessarily contradictory between them. In most subjects, different bodies have a convergent opinion and the discussion is more about who is the process owner rather than who is the idea owner.

The only exception are initiatives channeled through international institutions or the 'international community'. In this case, an official position or orientation needs first to be issued by the President with formal support from the party.

Entrepreneurship or entrepreneurial development is one of the topics that has been subject to constant recommendations from international institutions such as the World Bank and the African Development Bank.

The phenomenon seems not to be seen as a critical tool to foster development. The problem is that most politicians clearly separate 'entrepreneur' from 'businessman', the former being the undifferentiated 'poor citizen' and the second being 'the middle to upper class educated person' with real possibilities to thrive his way up to success. Many if not most of these individuals have low to middle (local) political influence. 
About bureaucracy and the general doing business concerns, there is a strong influence of the party to not dismantle the administrative structure of corporate-related issues. When asked about the reasons behind that, our interviewee replied that 'given the public wages range, one may speculate that many low-level public-servants make a living out of bureaucracy'. The same does not apply to official fee schedules. 'In Mozambique, you may lose your job if you cheat on that. Everybody knows the fees and tariffs for every public service'.

Access to capital is a major problem to entrepreneurship in the country. Interest rates have been too high for too long but the Central Bank is doing a good job about it. Financial system is efficient and credible.

Are entrepreneurs perceived as a threat to political power? 'No, but nobody is interested in making your life easier in this country. If you succeed, you will be controlled and you will share your gains...'

\section{(ii) Interview with the public servant policy-implementer - 1 individual}

This interviewee is a board member or equivalent in a public institution with direct responsibilities on small businesses / entrepreneurship.

The process of policy-implementation was reviewed. It was mentioned that in most cases there is no formal transmission of information or goals. Information is received through published legislation. If significant inquires arise from below hierarchical people, formal explanations are sent to the relevant minister's cabinet. If misinterpretations occur, usually it is because of ignorance or inability. There is no tradition or room for disobedience or boycott. Even less for sabotage. 'In some public departments of this country one can sometimes observe passivity or indifference. Have you heard the saying? The State pretends to pay us wages and we pretend to work hard...'

Entrepreneurship is a fashion concept, a buzzword. Nobody really believes in it but everybody keeps on mentioning its virtues. Government is willing to display some measures to animate the poor. Many are just looking for opening their 'barraquinha' ( $a$ very small shop) and get rid of a very bad payed job. But with no significant expectations or ambition. Why is that? Because people are conscious of their 'despreparo' (lack of skills), nothing else.

About bureaucracy, the idea is that there is nothing anybody can do about it. At the same time, for most people, it is not a real barrier. It is just a time-consuming challenge, some kind of natural selection test. The exception? Foreigners. In that case, bureaucracy could be used to discourage some unwanted strangers to make money in Mozambique or to keep them in an illegal / informal situation. In extreme cases, filed applications simply disappear, as many times as they are done, and there is never closure for certain demands.

As for the fee schedules, if they are not clear is because they were not defined and/or approved. The ordinary public servant would not play games with this type of thing. It is just too dangerous and people have already lost their jobs because of that.

In terms of funding facilities, they are very expensive and difficult to access given the requirements and the low credibility of most companies' accounts. Government could do more about it by reducing interest rates to entrepreneurial programs. 
Entrepreneurship is not something politicians want to avoid. It is simply something that is deemed to be neutral to their agendas. Therefore, they do not really commit to that, unless some type of real interest is perceived.

\section{(iii) Interview with the funding provider - 1 individual}

The person interviewed in this group was a senior executive of a leading financial institution responsible for funding decisions to entrepreneurial ventures.

The discussion begun with the way policymaking occurs in the country, especially in what relates to entrepreneurship. From this person's perspective, policymaking in Mozambique 'is no better or worse than in any other African country I have worked before'. From a pure formal perspective, the bill-passing process seems to be comparable to European countries'. It is difficult to understand though how some issues reach the top of the political agenda and others do not. International institutions play a significant role in this country, especially in subjects like poverty alleviation, HIV combat, etc. Entrepreneurship is identified as part of fighting poverty targets.

Public servants are very low educated and skilled. They do not seem to be capable of simply understanding the laws and regulations. Consequently, they are basically unable to put things in motion. In most cases, programs will only go live after the Minister himself/herself mediatizes it or engages into in loco visitation.

Bureaucracy is about defending the 'pequenos poderes' (power of the small). Eventually, there is always a way of resolving these constraints. For example, for financial institutions bureaucracy is 'a necessary evil' because information integrity and paper records are simply not reliable in this country.

Governments in Africa do not like entrepreneurship no more than any other thing that they do not fully control. Opportunity-driven entrepreneurship is nearly inexistent in Mozambique because there is no innovation /knowledge base in the country. Even incubation has no real meaning. It is a shame the absence of real science and technology programs from either international or national initiative. The last domestic call in this field was actually to finance public universities, not to foster innovation...

About the financing conditions to entrepreneurship, they are very challenging and most entrepreneurs can not grab any relevant chunk of capital. Most companies have no controlling systems in place and their accounts are 'a complete fiction'. The inexistence of venture capital funds reveal a void of investment opportunities.

Finally, fee schedules is a non-issue.

\section{(iv) Interview with the expert - 1 individual}

The expert identified is a very experienced and highly educated individual who works both as a business and government consultant and as a private university lecturer.

Policymaking is a complicated process. It deals with far too many people: the party, the council of ministers, different governmental cabinets, the president, tons of consultants and advisors, parliamentary reps, just to mention the most relevant. Bottom-line? It is not an effective process and important decisions are taken last minute usually under significant international pressure. 
The chain of command works also very poorly. First, because ministers themselves do not always know exactly the details about 'their' bills and, second, because many of the public servants reporting to them, highly ranked, are insufficiently skilled and educated to implement tough programs. Additionally, many of them are not fully empowered visà-vis their subordinates who were appointed by a higher officer.

Bureaucracy is impossible to detonate in this country. For many people, their salary is a tiny percentage of what they make with bureaucracy-related bribery. Some of them do not actually do any of the tasks outlined in their job description. They use it as a way of making illegal money.

Government has no real strategy for entrepreneurship. It is not such a relevant matter. Not even incubation, one of the easiest things to do, has expression. Maybe the moment some real entrepreneurial ventures start to succeed, not just the 'barraquinhas', government will start considering entrepreneurship as a real thing. Another important thought on this topic is the role played by the party's youth. They disregard entrepreneurship and look only for political opportunities. If only they would change their mindset towards business venturing...

Access to capital is a tremendous concern. Ventures are too small and have no bargaining power over banks. Business angels are not significant because of trust issues. Microcredit works well for micro-entrepreneurs.

On the fee schedules, apart from very limited exceptions, there are no reasons for concern. Nevertheless, in local /regional public departments one can expect to be played on that issue. On the other hand, public services with significant money transaction have been subject to innovative measures: fee bank-deposit prior to the conclusion of the transaction, and, more recently, the use of automatic paying machines.

\section{(v) Interviews with the entrepreneurs - six individuals}

As mentioned earlier, actors from this category are from the following provinces: MaputoCity, Maputo-Province, Sofala, Tete, Niassa, and Nampula, one per location, four men, two women, medium qualified, operating in the following economic activities: agriculture, food trading, hospitality, restauration, business services, and bakery. The goal was obviously to have a national representation of entrepreneurial experiences to assess also context sensitivity.

About policymaking, none of the entrepreneurs expressed strong feelings on that. The two from Maputo-City and Maputo-Province seemed to follow politics closer than the others. The four entrepreneurs from central and northern regions mentioned that policymaking had no significant relevance for their business activities although they all acknowledge that government is a key actor for the economic development of the country.

About the public agencies in charge of supporting entrepreneurship, all six entrepreneurs had no hesitation in classifying them as 'nearly useless' or simply 'bureaucratic desks'. Because they do not identify a clear entrepreneurial policy, they struggle to evaluate its direction. None of them had done any research about any existing program. The wordof-mouth seems to be the most effective tool to make awareness of public support. Public servants working in those agencies are also seen as 'functionaries' not adding any specific 
value. One quoted example was the application to a public incubator in the region of Maputo. The application could not be completed due to missing documents. But no followup or any kind of help were made available. For the four entrepreneurs in the Center and North, no public incubation facilities were available at the start up stage.

Bureaucracy is the key issue for all six entrepreneurs, especially for the four in central and norther side of the country. It starts with the incorporation and goes on and on with every single administrative interaction. 'It is slow and expensive and adds no value. Servants are always fishing for bribery and even though things do not get done in due time'.

Capital limitations are a concern to all six entrepreneurs. Interest rates make money inaccessible for borrowing. Microcredit is the only viable option but amounts are too small to develop the business in a reasonable time-frame. Private equity, venture capital, and business angels seem to be strange concepts to these interviewees.

Government does not fear entrepreneurship. It simply does not care about it. Entrepreneurship in Mozambique means informal economy, 'barraquinhas', and poverty alleviation. Anything other than that is pure business, not entrepreneurship.

\section{Conclusion}

This research supports the basic theoretical assumptions outlined in the literature review.

For example, Juma et al (2017) hypothesis that the positive role of government on entrepreneurship takes place by facilitating legal infrastructure and providing funding facilities was mentioned by all interviewees.

The ideas behind Shane (2009) and Mthanti \& Ojah (2017) about the importance of entrepreneurial meaningfulness and entrepreneurial orientation are also confirmed by these interviews, both explicitly and implicitly.

Naudé (2013) conclusions about policy focusing on pulling entrepreneurial ability instead of entrepreneurial activity receive also confirmation from this investigation.

Schillo et al (2016) importance of institutional variables to entrepreneurship is referred by all respondents but, curiously, by absence of clear policy, entrepreneurs cannot see it.

Kiss et al (2012) references on difficult access to capital, inconsistent governmental regulation, and unavailability of business locations are also explicitly referred by all interviewees.

Amankwah-Amoah (2018) evidence that entrepreneurs are 'potential political threats' in Ghana is not confirmed in Mozambique. One may speculate that the low level of entrepreneurial sophistication may account for that perception.

Mota \& Moreira (2017) proposition about the importance of governments attracting both external and internal entrepreneurs receives negative support from this study. In Mozambique, according to one of the interviews, foreigners are not especially welcomed. Of course, this may be an issue for entrepreneurial development but more evidence is required to support thorough conclusions. 
McDade \& Spring (2005) conclusions about the new generation of African entrepreneurs demanding 'business-friendly laws and regulations, government policies, and programs', and dialoguing governments is not supported either in this study. Again, the lack of a real opportunity-driven entrepreneurial base may explain this type of response.

Finally, we must stress the limited character of this research based on ten interviews. Future directions for this research include enlarging the scope of the literature review and increasing the number of interviewees and their territorial representation, including rural versus urban and male versus female entrepreneurship.

\section{References}

Adusei, M. (2016). «Does Entrepreneurship Promote Economic Growth in Africa?». African Development Review. 28 (2): 201-214.

Amankwah-Amoah, J. (2018). «Revitalising Serial Entrepreneurship in Sub-Saharan Africa: Insights From a Newly Emerging Economy». Technology Analysis \& Strategic Management. 30 (5), 499-511.

Amankwah-Amoah, J. \& Osabutery, E.L.C. \& Egbetokun, A. (2018a). «Contemporary Challenges and Opportunities of Doing Business in Africa». Technological Forecasting \& Social Change. 131 (3), 171-174.

Amankwah-Amoah, J. \& Egbetokun, A. \& Osabutery, E.L.C. (2018b). «Meeting the $21^{\text {st }}$ Century Challenges of Doing Business in Africa». Technological Forecasting \& Social Change. 131 (3), 336-338.

Asongu, S. \& Nwachukwu, J. \& Orim, S-M.I. (2018). «Mobile Phones, Institutional Quality, and Entrepreneurship in Sub-Saharan Africa». Technological Forecasting \& Social Change. 131 (3), 183-203.

Barasa, L. \& Knoben, J. \& Vermeulen, P. \& Kimuyu, P. \& Kinyanjui, B. (2017). «Institutions, Resources, and Innovation in East Africa: A Firm Level Approach». Research Policy. 46 (3), 280-291.

Braxiova, Z. (2010). «Unlocking Productive Entrepreneurship in Africa's Least Developed Countries». African Development Review. 22 (3): 440-451.

Braxiová, Z. \& Ncube, M. \& Bicaba, Z. (2015). «Skills and Youth Entrepreneurship in Africa: Analysis with Evidence form Swaziland». World Development. 67 (1): 11-26.

Cunningham, P. (2015). Insights into Open Innovation and ICT Entrepreneurship in Africa. Proceedings of the 2015 IEEE International Symposium on Technology in Society (ISTAS).

Hilson, G. \& Hilson, A. \& Maconachie, R. (2018). «Opportunity or Necessity? Conceptualizing Entrepreneurship at African Small-Scale Mines». Technological Forecasting \& Social Change. 131 (6): 286-302.

Islam, A. (2015). «Entrepreneurship and the Allocation of Government Spending Under Imperfect Markets». World Development. 70 (1): 108-121.

Juma, N.A., \& James, C.D. \& Kwesiga, E. (2017). Sustainable Entrepreneurship in SubSaharan Africa: the Collaborative Multi-System Model, Journal of Small Business and Entrepreneurship, 29 (3): 211-235. 
Kiss, A.N. \& Danis, W.M. \& Cavusgil, S.T. (2012). «International Entrepreneurship Research in Emerging Economies: A Critical Review and Research Agenda». Journal of Business Venturing, 27 (2): 266-290.

Kshetri, N. (2016). «Creation, deployment, diffusion, and export of Sub-Saharan Africaoriginated information technology-related innovations». International Journal of Information Management, 36 (12): 1274-1287.

Libombo, D.B. \& Dinis, A. (2015). «Entrepreneurship Education in the Context of Developing Countries: Study of the Status and the Main Barriers in Mozambican Higher Education Institutions». Journal of Developmental Entrepreneurship, 20 (3); 1-26.

Lührmann, A. \& Tannenberg, M. \& Lindberg, S.I. (2018). «Regimes of the World (RoW): Opening New Avenues for the Comparative Study of Political Regimes». Politics and Governance, 6 (1): 60-77.

Luo, Y. \& Junkunc, M. (2008). «How Private Enterprises Respond to Government Bureaucracy in Emerging Economies: The Effects of Entrepreneurial Type and Governance». Strategic Entrepreneurship Journal, 2 (2): 133-153.

McDade, B.E. \& Spring, A. (2005). «The 'New Generation of African Entrepreneurs': Networking to Change the Climate for Business and Private Sector-Led Development». Entrepreneurship \& Regional Development, 17 (1): 17-42.

Mehari, A.T. \& Belay, C.F. (2017). Challenges and Prospects of Entrepreneurship Development and Job Creation for Youth Unemployed: Evidence from Addis Ababa and Dire Dawa City Administrations, Ethiopia. Journal of Innovation and Entrepreneurship, 6(11): 1-22.

Mota, J.H.F. \& Moreira, A.C. (2017). «Determinants of the Capital Structure of Portuguese Firms with Investments in Angola». South African Journal of Economic and Management Sciences, 20 (1): 1-11.

Mthanti, T. \& Ojah, K. (2017). «Entrepreneurial Orientation (EO), Measurement and Policy Implications of Entrepreneurship at the Macroeconomic Level». Research Policy, 46 (4): 724-739.

Naudé, W. (2013). Entrepreneurship and Economic Development: Theory, Evidence, and Policy. Discussion Paper No. 7507, Institute for the Study of Labor, Bonn, Gemany.

Ojeaga, P. I. (2015). «Can Africa's Young Drive Innovation? Investigating the Effect of Entrepreneurial Innovation on Economic Growth in Africa». Journal of Applied Quantitative Methods, 10 (4): 15-26.

Robson, P.J.A. \& Haugh, H.M. \& Obeng, B.A. (2009). «Entrepreneurship and Innovation in Ghana: Enterprising Africa». Small Business Economics, 32 (3): 331-350.

Schillo, R.S. \& Persaud, A. \& Jin, M. (2016). «Entrepreneurial Readiness in the Context of National Systems of Entrepreneurship». Small Business Economics. 46 (5): 619-637.

Shane, S. (2009). «Why Encouraging More People to Become Entrepreneurs is Bad Public Policy». Small Business Economics. 33 (2): 141-149. 